\title{
Type of preoperative therapy and stage-specific survival after surgery for rectal cancer: a nationwide population-based cohort study
}

\author{
Steven L. Bosch ${ }^{1} \cdot$ Rob H. A. Verhoeven ${ }^{2} \cdot$ Valery E. P. P. Lemmens ${ }^{2,3} \cdot$ Femke Simmer $^{1}$ (D) Philip Poortmans ${ }^{4}$. \\ Johannes H. W. de Wilt ${ }^{5}$. Iris D. Nagtegaal ${ }^{1}$
}

Received: 10 April 2019 / Revised: 1 July 2019 / Accepted: 26 July 2019/Published online: 28 August 2019

(C) The Author(s) 2019

\begin{abstract}
Preoperative chemoradiation therapy (CRT) may induce downstaging in rectal cancer (RC). Short-course radiation therapy (SCRT) with immediate surgery does not cause substantial downstaging. However, the TNM classification adds the " $y$ " prefix in both groups to indicate possible treatment effects. We aim to compare stage-specific survival in these patients. RC patients treated with surgery only, preoperative SC-RT followed by surgery within 10 days, or preoperative CRT, and diagnosed between 2008 and 2014 were included in this population-based study. Clinicopathological and outcome characteristics were analyzed. The study included 11,925 patients. Large discrepancies existed between clinical and pathological stages after surgery only. Surgery-only patients were older with more comorbidities compared with SC-RT and CRT and had worse 5-year survival $(64 \%, 76 \%$, and $74 \%$, respectively; $p<0.001)$. Five-year survival for stage I was similar after CRT and SC-RT ( $85 \%$ vs. $85 \% ; p=0.167)$ and comparable between CRT-treated patients with stage I and those reaching a pathological complete response (pCR; $85 \%$ vs. $89 \% ; p=$ 0.113). CRT was independently associated with worse overall survival compared with SC-RT for stage II (HR 1.57 [95\%CI 1.271.95]; $p<0.001$ ) and stage III (HR 1.43 [95\%CI 1.23-1.70]; $p<0.001$ ). Stage I disease after CRT has an excellent prognosis, comparable with pCR and with same-stage SC-RT-treated patients without regression. Stage II or III after CRT has worse prognosis than after SC-RT with immediate surgery. TNM should take the impact of preoperative therapy type on stagespecific survival into account. In addition, clinical stage was a poor predictor of pathological stage.
\end{abstract}

Keywords Rectal cancer $\cdot$ pTNM $\cdot$ ypTNM $\cdot$ Downstaging $\cdot$ Preoperative therapy $\cdot$ TNM stage $\cdot$ Survival

\section{Introduction}

The standard of care for rectal cancer (RC) patients is total mesorectal excision (TME) with or without preoperative

Steven L. Bosch

s.bosch@pamm.nl

1 Department of Pathology, Radboud University Medical Center, P.O. Box 9101, 6500 HB Nijmegen, The Netherlands

2 Netherlands Comprehensive Cancer Organization/Netherlands Cancer Registry, P.O. Box 19079, 3501 DB Utrecht, The Netherlands

3 Department of Public Health, Erasmus MC University Medical Centre, P.O. Box 2040, 3000 CA Rotterdam, The Netherlands

4 Department of Radiation Oncology, Institut Curie, 26 Rue d'Ulm, 75248 Paris Cedex 05, France

5 Department of Surgery, Radboud University Medical Center, Nijmegen, The Netherlands therapy depending on clinical stage. For patients with locally advanced RC, preoperative treatment consists of chemoradiation therapy (CRT) intended to reduce local recurrence rates and to facilitate radical surgery by inducing tumor regression and possible downstaging $[1,2]$. Significant tumor and nodal downstaging is reported in patients treated with CRT and depends on factors such as tumor type, clinical stage, and interval between radiation therapy and surgery [3-7]. Downstaging is associated with an improved prognosis, especially in $8-24 \%$ of patients with a pathological complete response (pCR) $[1,6,8,9]$. The TNM staging system $[10,11]$ recommends adding the prefix " $y$ " to the TNM stage after preoperative therapy to indicate that a tumor may have undergone treatment-induced response or regression.

Especially in Western European countries, patients may also undergo preoperative short-course radiation therapy (SC-RT) followed by immediate surgery [12-15]. Randomized trials show a small downstaging effect in these patients $[13,14]$, and according to the definitions of the TNM 
classification, the "y" prefix should be added. However, downstaging does not occur after SC-RT if the overall treatment time (i.e., interval between start of radiation therapy and rectal resection) does not exceed 10 days [16]. The prognostic significance of ypTNM stage for patients in these groups (with vs. without possible downstaging) is still unclear. Due to the differences in levels of downstaging between groups of patients treated either with preoperative SC-RT followed by immediate surgery or with CRT [17], it may be hypothesized that the prognostic implications of the " $y$ " prefix depend on the type of preoperative therapy received, which limits the prognostic value of staging.

The purpose of this study is therefore to investigate on a population level whether stage-specific overall survival is different between patients treated with either SC-RT followed by surgery within 10 days after start of treatment (no tumor regression expected; ypTNM by definition, but may reflect pTNM) or preoperative long-course CRT (intended to induce tumor regression; ypTNM) and to compare results with patients who underwent surgery only (pTNM).

\section{Patients and methods}

\section{Study design and patient selection}

A population-based approach was employed using data from the nationwide Netherlands Cancer Registry (NCR). This institute collects data on all newly diagnosed cancer patients in the Netherlands since 1989. The registration is primarily based on notification by the Dutch national digital pathology registry (PALGA). Patient and clinicopathological data are routinely collected from medical records by specially trained data managers. Tumor location and histology is registered according to the ICD-O3 classification. Follow-up data and vital status are retrieved by linkage to the nationwide population registries network.

Patients with RC diagnosed between January 2008 and December 2014 who underwent a surgical resection were selected from the NCR. Clinicopathological characteristics and overall survival (including TNM stage-specific survival) were compared between patients treated with surgery only, preoperative SC-RT with an overall treatment time that did not exceed 10 days, and preoperative long-course CRT. The maximum interval of 10 days between start of SC-RT and surgery was chosen, since tumor regression is not likely to occur within this timeframe [16]. For patients in the CRT group, an interval of at least 63 days (duration of CRT +4 weeks to provide the opportunity for tumor regression) and no longer than 182 days ( 6 months; arbitrary) was required.

Cases were excluded if the date of surgery was not available or if there was presence of distant metastases at time of surgery or missing data regarding distant metastases. The same was true for cases with histopathological tumor type other than adenocarcinoma, mucinous carcinoma, or signet ring cell carcinoma. Other exclusion criteria were missing values for pathological $\mathrm{T}$ or $\mathrm{N}$ categories and surgical procedures other than a low anterior resection (LAR), Hartmann's procedure, abdominoperineal excision (APE), or intersphincteric resection.

Comorbidity was only registered in the NCR for one specific region in the Netherlands, covering $12 \%$ of the population. A subgroup analysis of this data was performed.

\section{Preoperative therapy}

The prevailing RC clinical guideline [18] during the inclusion period recommended preoperative SC-RT for primarily resectable RC (with the exception of cT1N0 tumors) consisting of $5 \times 5$ Gy followed by surgery within 1 week. Long-course CRT consisting of 45-50 Gy given in 25 fractions of 1.82.0 Gy per day with concurrent oral chemotherapy (capecitabine $825-1000 \mathrm{mg} / \mathrm{m}^{2}$ twice daily) and followed by surgery within 4-6 weeks was indicated for locally advanced RC (i.e., patients with clinical N2 disease, cT4 tumors, or tumors with suspected involvement of the mesorectal fascia on imaging). Patients treated with surgery only either had cT1N0 disease or were unfit or did not give consent to undergo preoperative treatment.

\section{Statistical analysis}

All data was entered in a database and analyzed using IBM SPSS Statistics for Windows, version 22.0, Armonk, NY: IBM Corp. Categorical variables were analyzed using the $\chi^{2}$ test. Cumulative overall survival was analyzed using the Kaplan-Meier method with log rank test. Univariable and multivariable analyses were performed by entering all applicable clinical and pathological factors in a Cox regression model. A $p$ value of $<0.05$ was considered statistically significant whereas a $p$ value of $<0.1$ was taken to reflect a trend towards significance.

\section{Results}

\section{Patient selection}

The initial search of the NCR database identified 19,737 patients. Figure 1 depicts the selection process, resulting in the inclusion of a total of 11,925 patients (2590 with surgery only, 4534 with SC-RT, and 4801 with CRT).

\section{Clinicopathological factors}

Table 1 provides the clinical and pathological characteristics. Median interval between start of SC-RT and surgery was 
Fig. 1 Flow diagram showing the selection process. SC-RT, shortcourse radiation therapy; CRT, chemoradiation therapy; NOS, not otherwise specified; $\mathrm{pT}$, pathological tumor category; $\mathrm{pN}$, pathological nodal category

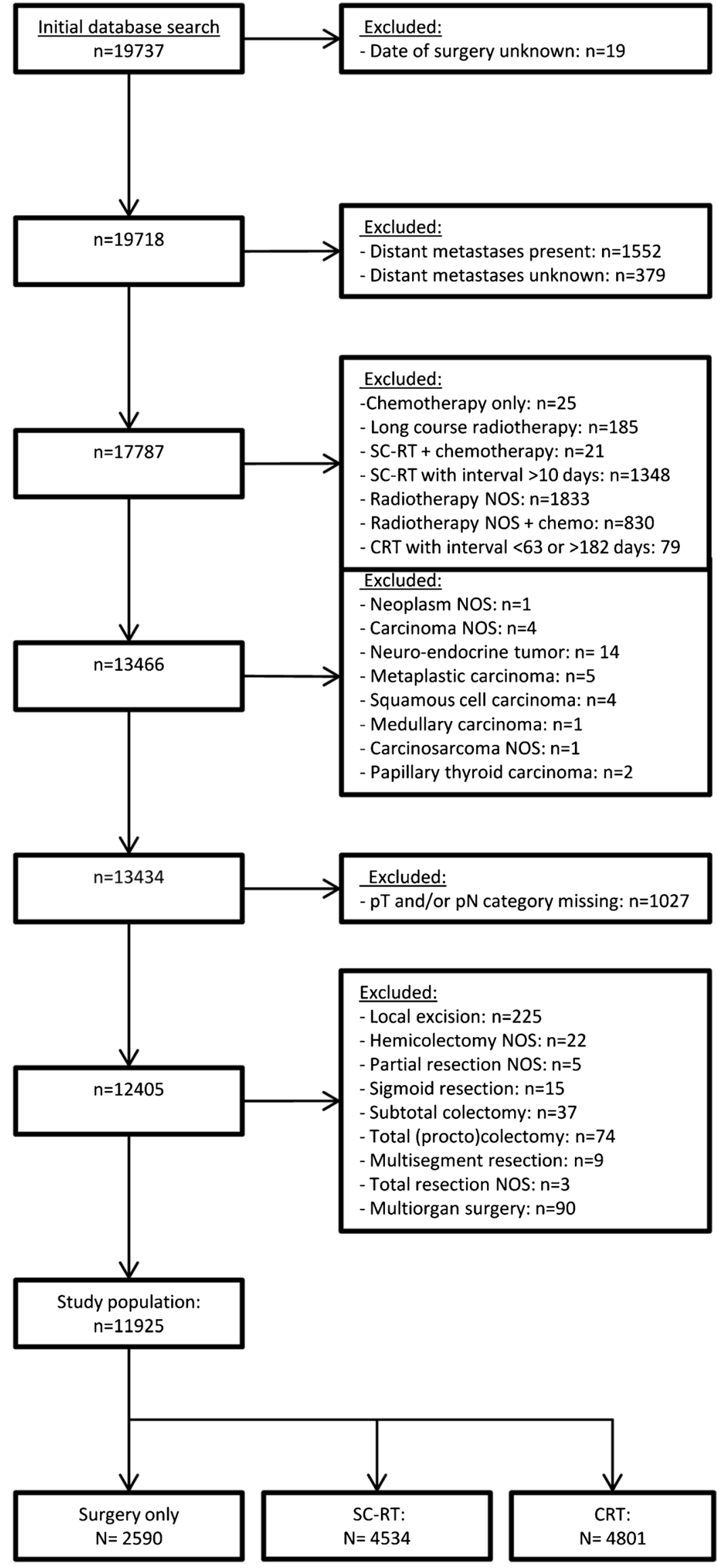


Table 1 Clinicopathological characteristics of patients treated with surgery only, SC-RT, and CRT

\begin{tabular}{|c|c|c|c|c|c|c|c|c|c|}
\hline & \multicolumn{2}{|l|}{ Total } & \multicolumn{2}{|c|}{ Surgery only } & \multicolumn{2}{|c|}{ SC-RT } & \multicolumn{2}{|l|}{ CRT } & \multirow[t]{2}{*}{$p$ value } \\
\hline & $n$ & $\%$ & $n$ & $\%$ & $n$ & $\%$ & $n$ & $\%$ & \\
\hline Total & 11,925 & & 2590 & & 4534 & & 4801 & & \\
\hline Gender & & & & & & & & & 0.092 \\
\hline Male & 7610 & 63.8 & 1608 & 62.1 & 2899 & 63.9 & 3103 & 64.6 & $0.485^{\mathrm{a}}$ \\
\hline Female & 4315 & 36.2 & 982 & 37.9 & 1635 & 36.1 & 1698 & 35.4 & \\
\hline Age at diagnosis & & & & & & & & & $<0.001$ \\
\hline $0-44$ & 342 & 2.9 & 48 & 1.9 & 89 & 2.0 & 205 & 4.3 & \\
\hline $45-59$ & 2583 & 21.7 & 334 & 12.9 & 886 & 19.5 & 1363 & 28.4 & \\
\hline $60-74$ & 6078 & 51.0 & 1171 & 45.2 & 2289 & 50.5 & 2618 & 54.5 & \\
\hline $75+$ & 2922 & 24.5 & 1037 & 40.0 & 1270 & 28.0 & 615 & 12.8 & \\
\hline Clinical $\mathrm{T}$ category & & & & & & & & & $<0.001$ \\
\hline $\mathrm{cT} 1$ & 302 & 3.1 & 147 & 8.0 & 133 & 3.8 & 22 & 0.5 & \\
\hline $\mathrm{cT} 2$ & 2656 & 26.9 & 800 & 43.7 & 1415 & 40.1 & 441 & 9.8 & \\
\hline cT3 & 6070 & 61.4 & 783 & 42.8 & 1933 & 54.7 & 3354 & 74.2 & \\
\hline cT4 & 852 & 8.6 & 99 & 5.4 & 52 & 1.5 & 701 & 15.5 & \\
\hline Missing & 2045 & & 761 & & 1001 & & 283 & & \\
\hline Clinical $\mathrm{N}$ category & & & & & & & & & $<0.001$ \\
\hline $\mathrm{cNO}$ & 5272 & 49.7 & 1824 & 80.7 & 2594 & 65.9 & 854 & 19.4 & \\
\hline $\mathrm{cN} 1$ & 3284 & 31.0 & 348 & 15.4 & 1193 & 30.3 & 1743 & 39.6 & \\
\hline $\mathrm{cN} 2$ & 2043 & 19.3 & 88 & 3.9 & 148 & 3.8 & 1807 & 41.0 & \\
\hline Missing & 1326 & & 330 & & 599 & & 397 & & \\
\hline Clinical TNM stage & & & & & & & & & $<0.001$ \\
\hline Stage I & 1879 & 20.2 & 789 & 45.2 & 989 & 30.3 & 109 & 2.3 & \\
\hline Stage II & 2117 & 22.7 & 519 & 29.8 & 930 & 28.5 & 686 & 15.5 & \\
\hline Stage III & 5327 & 57.1 & 436 & 25.0 & 1341 & 41.1 & 3602 & 82.2 & \\
\hline Missing & 2602 & & 846 & & 1274 & & 482 & & \\
\hline Type of resection & & & & & & & & & $<0.001$ \\
\hline Sphincter saving ${ }^{\mathrm{b}}$ & 8161 & 68.4 & 2152 & 83.1 & 3361 & 74.1 & 2648 & 55.2 & \\
\hline Non-sphincter saving ${ }^{\mathrm{c}}$ & 3764 & 31.6 & 438 & 16.9 & 1173 & 25.9 & 2153 & 44.8 & \\
\hline Pathological T category & & & & & & & & & $<0.001$ \\
\hline (y)pT0 & 979 & 8.2 & 5 & 0.2 & 34 & 0.7 & 940 & 19.6 & \\
\hline (y)pT1 & 1050 & 8.8 & 380 & 14.7 & 336 & 7.4 & 334 & 7.0 & \\
\hline (y)pT2 & 4073 & 34.2 & 893 & 34.5 & 1852 & 40.8 & 1328 & 27.7 & \\
\hline (y)pT3 & 5450 & 45.7 & 1206 & 46.6 & 2237 & 49.3 & 2007 & 41.8 & \\
\hline (y)pT4 & 373 & 3.1 & 106 & 4.1 & 75 & 1.7 & 192 & 4.0 & \\
\hline Pathological N category & & & & & & & & & $<0.001$ \\
\hline (y)pN0 & 8098 & 67.9 & 1775 & 68.5 & 2958 & 65.2 & 3365 & 70.1 & \\
\hline (y)pN1 & 2632 & 22.1 & 568 & 21.9 & 1081 & 23.8 & 983 & 20.5 & \\
\hline (y)pN2 & 1195 & 10.0 & 247 & 9.5 & 495 & 10.9 & 453 & 9.4 & \\
\hline Pathological TNM stage & & & & & & & & & $<0.001$ \\
\hline Stage 0 & 895 & 7.5 & 4 & 0.2 & 25 & 0.6 & 866 & 18.0 & \\
\hline Stage I & 4070 & 34.1 & 1058 & 40.8 & 1705 & 37.6 & 1307 & 27.2 & \\
\hline Stage II & 3133 & 26.3 & 713 & 27.5 & 1228 & 27.1 & 1192 & 24.8 & \\
\hline Stage III & 3827 & 32.1 & 815 & 31.5 & 1576 & 34.8 & 1436 & 29.9 & \\
\hline CRM involvement ${ }^{\mathrm{d}}$ & & & & & & & & & $<0.020$ \\
\hline Absent & 9605 & 92.4 & 1981 & 91.6 & 3695 & 93.3 & 3929 & 92.0 & $0.018 *$ \\
\hline Present & 788 & 7.6 & 181 & 8.4 & 264 & 6.7 & 343 & 8.0 & \\
\hline Missing & 1532 & & 428 & & 575 & & 529 & & \\
\hline
\end{tabular}


Table 1 (continued)

\begin{tabular}{|c|c|c|c|c|c|c|c|c|c|}
\hline & \multicolumn{2}{|l|}{ Total } & \multicolumn{2}{|c|}{ Surgery only } & \multicolumn{2}{|c|}{ SC-RT } & \multicolumn{2}{|l|}{ CRT } & \multirow[t]{2}{*}{$p$ value } \\
\hline & $n$ & $\%$ & $n$ & $\%$ & $n$ & $\%$ & $n$ & $\%$ & \\
\hline Histological type & & & & & & & & & 0.009 \\
\hline Adenocarcinoma & 11,049 & 92.7 & 2436 & 94.1 & 4208 & 92.8 & 4405 & 91.8 & $0.158 *$ \\
\hline Mucinous carcinoma & 825 & 6.9 & 144 & 5.6 & 308 & 6.8 & 373 & 7.8 & \\
\hline Signet ring cell carcinoma & 51 & 0.4 & 10 & 0.4 & 18 & 0.4 & 23 & 0.5 & \\
\hline Postoperative CTx & & & & & & & & & 0.013 \\
\hline No & 11,175 & 93.7 & 2395 & 92.5 & 4263 & 94.0 & 4517 & 94.1 & \\
\hline Yes & 750 & 6.3 & 195 & 7.5 & 271 & 6.0 & 284 & 5.9 & \\
\hline
\end{tabular}

$S C-R T$ short-course radiation therapy, $C R T$ chemoradiation therapy, $C R M$ circumferential resection margin, $C T x$ chemotherapy

${ }^{\text {a }} \mathrm{SC}-\mathrm{RT}$ vs. CRT

${ }^{\mathrm{b}}$ Includes 6887 patients with low anterior resection, 1186 patients with Hartmann's procedure, and 88 patients with intersphincteric resection

${ }^{\mathrm{c}}$ Patients with abdominoperineal excision

${ }^{\mathrm{d}}$ Circumferential resection margin $(\mathrm{CRM})$ involvement was defined as tumor distance to the $\mathrm{CRM} \leq 1 \mathrm{~mm}$

8 days (range $0-10$ ), and in the CRT group, the median interval was 100 days (range 63-182). Patients in the surgery-only group were older than those in the SC-RT group, who in turn were older than the CRT-treated patients (age $>75$ years; $40 \%$,

Table 2 Correlation between clinical and pathological stages

\begin{tabular}{|c|c|c|c|c|c|c|c|}
\hline \multirow[t]{3}{*}{$N=9323^{\mathrm{a}}$} & & \multicolumn{6}{|c|}{ Clinical stage } \\
\hline & & \multicolumn{2}{|c|}{ Stage I } & \multicolumn{2}{|c|}{ Stage II } & \multicolumn{2}{|c|}{ Stage III } \\
\hline & & $n$ & $\%$ & $n$ & $\%$ & $n$ & $\%$ \\
\hline \multirow[t]{6}{*}{ Surgery only } & \multicolumn{7}{|c|}{ Pathological stage } \\
\hline & Stage 0 & 2 & 0.3 & 1 & 0.2 & 0 & 0.0 \\
\hline & Stage I & 481 & 61.0 & 146 & 28.1 & 81 & 18.6 \\
\hline & Stage II & 154 & 19.5 & 237 & 45.7 & 108 & 24.8 \\
\hline & Stage III & 152 & 19.3 & 135 & 26.0 & 247 & 56.7 \\
\hline & Total & 789 & 100.0 & 519 & 100.0 & 436 & 100.0 \\
\hline \multirow[t]{6}{*}{ SC-RT } & \multicolumn{7}{|c|}{ Pathological stage } \\
\hline & Stage 0 & 15 & 1.5 & 1 & 0.1 & 4 & 0.3 \\
\hline & Stage I & 535 & 54.1 & 286 & 30.8 & 359 & 26.8 \\
\hline & Stage II & 199 & 20.1 & 368 & 39.6 & 320 & 23.9 \\
\hline & Stage III & 240 & 24.3 & 275 & 29.6 & 658 & 49.1 \\
\hline & Total & 989 & 100.0 & 930 & 100.0 & 1341 & 100.0 \\
\hline \multirow[t]{6}{*}{ CRT } & \multicolumn{7}{|c|}{ Pathological stage } \\
\hline & Stage 0 & 30 & 29.7 & 129 & 19.3 & 601 & 16.9 \\
\hline & Stage I & 40 & 39.6 & 205 & 30.7 & 898 & 25.3 \\
\hline & Stage II & 18 & 17.8 & 235 & 35.2 & 821 & 23.1 \\
\hline & Stage III & 13 & 12.9 & 99 & 14.8 & 1230 & 34.6 \\
\hline & Total & 101 & 100.0 & 668 & 100.0 & 3550 & 100.0 \\
\hline
\end{tabular}

$S C-R T$ short-course radiation therapy, $C R T$ chemoradiation therapy

${ }^{\text {a }}$ Cases with missing values for clinical TNM stage were excluded $(n=$ 2602)
$28 \%$, and $13 \%$ in the surgery-only, SC-RT, and CRT groups, respectively; $p<0.001$ ). Other factors that were significantly associated with the type of preoperative treatment were $\mathrm{cT}$ category, $\mathrm{cN}$ category, cTNM stage, type of resection, $\mathrm{pT}$ category, $\mathrm{pN}$ category, pTNM stage, CRM involvement, histological type, and presence of postoperative chemotherapy. Patients in the CRT group showed ypT0 in 20\% of cases and had a reduced rate of (y)pT2 and (y)pT3 tumors compared with those in the surgery-only and SC-RT groups $(p<0.001)$. A pCR (ypT0N0) occurred in $18 \%$ of cases after CRT.

A subgroup analysis of cases with available comorbidity data $(n=1270)$ showed a higher rate of comorbidities in the surgery-only group compared with both the SC-RT and CRT groups with $\geq 2$ comorbidities in $45 \%, 35 \%$, and $25 \%$ of cases for surgery only, SC-RT, and CRT, respectively $(p<0.001$ for surgery only vs. CRT; $p=0.006$ for surgery only vs. SC-RT; $p=0.003$ for SC-RT vs. CRT).

\section{Correlation between cTNM and (y)pTNM}

The data showed substantial discrepancies between clinical and pathological TNM stages (Table 2). Patients with suspected LN on clinical imaging had histopathology showing nodal disease in $57 \%, 49 \%$, and $35 \%$ of cases that were treated with surgery only, SC-RT, and CRT, respectively $(p<0.001)$. Patients with clinical stage I disease had histopathological nodal involvement in 19\%, $24 \%$, and $13 \%$ after surgery only, SC-RT, and CRT, respectively $(p=0.004)$. For patients with clinical stage II, this was $26 \%, 30 \%$, and $15 \%$, respectively $(p<0.001)$. In the CRT group, there was complete tumor regression in $30 \%, 19 \%$, and $17 \%$ of cases for patients with clinical stage I, II, and III disease, respectively $(p<0.001)$. 
Table 3 Overall survival

\begin{tabular}{|c|c|c|c|c|}
\hline & Cumulative 5-year overall survival & $p$ value $^{\mathrm{a}}$ & HR & $95 \% \mathrm{CI}$ \\
\hline Overall & $73 \%$ & & & \\
\hline Preoperative therapy & & $<0.001$ & & \\
\hline SC-RT & 76.3 & $0.147^{\dagger}$ & 1.00 & - \\
\hline CRT & 73.5 & & 1.07 & $0.96-1.19$ \\
\hline None (surgery only) & 64.1 & & 1.73 & $1.55-1.94$ \\
\hline Gender & & $<0.001$ & & \\
\hline Male & 71.3 & & 1.00 & - \\
\hline Female & 76.0 & & 0.77 & $0.70-0.85$ \\
\hline Age at diagnosis & & $<0.001$ & & \\
\hline $0-44$ & 85.2 & & 1.00 & - \\
\hline $45-59$ & 82.0 & & 1.18 & $0.81-1.72$ \\
\hline $60-74$ & 76.9 & & 1.76 & $1.23-2.52$ \\
\hline $75+$ & 56.1 & & 4.10 & $2.87-5.87$ \\
\hline Clinical T category & & $<0.001$ & & \\
\hline cT1 & 75.0 & & 1.00 & - \\
\hline $\mathrm{cT} 2$ & 78.7 & & 0.99 & $0.70-1.39$ \\
\hline cT3 & 73.1 & & 1.36 & $0.98-1.89$ \\
\hline cT4 & 61.0 & & 2.15 & $1.51-3.05$ \\
\hline Missing & 71.2 & & 1.52 & $1.09-2.12$ \\
\hline Clinical $\mathrm{N}$ category & & 0.007 & & \\
\hline cN0 & 74.2 & & 1.00 & - \\
\hline cN1 & 71.9 & & 1.10 & $0.99-1.23$ \\
\hline $\mathrm{cN} 2$ & 73.6 & & 0.98 & $0.84-1.13$ \\
\hline Missing & 70.6 & & 1.22 & $1.08-1.38$ \\
\hline Clinical TNM stage & & $<0.001$ & & \\
\hline Stage I & 78.9 & & 1.00 & - \\
\hline Stage II & 72.0 & & 1.46 & $1.23-1.73$ \\
\hline Stage III & 72.4 & & 1.38 & $1.18-1.61$ \\
\hline Missing & 71.5 & & 1.51 & $1.29-1.77$ \\
\hline Type of resection & & 0.004 & & \\
\hline Sphincter saving & 74.0 & & 1.00 & - \\
\hline Non-sphincter saving & 71.1 & & 1.15 & $1.05-1.26$ \\
\hline Pathological T category & & $<0.001$ & & \\
\hline pT0 & 87.2 & & 0.73 & $0.54-0.99$ \\
\hline pT1 & 82.0 & & 1.00 & - \\
\hline pT2 & 81.0 & & 1.14 & $0.92-1.41$ \\
\hline pT3 & 65.2 & & 2.22 & $1.81-2.71$ \\
\hline pT4 & 45.9 & & 4.50 & $3.48-5.82$ \\
\hline Pathological N category & & $<0.001$ & & \\
\hline pNo & 79.2 & & 1.00 & - \\
\hline $\mathrm{pN} 1$ & 67.2 & & 1.65 & $1.49-1.84$ \\
\hline $\mathrm{pN} 2$ & 47.6 & & 3.13 & $2.79-3.51$ \\
\hline Pathological stage & & $<0.001$ & & \\
\hline Stage 0 & 89.2 & & 0.62 & $0.47-0.83$ \\
\hline Stage I & 83.3 & & 1.00 & - \\
\hline Stage II & 71.5 & & 1.76 & $1.55-2.00$ \\
\hline Stage III & 60.9 & & 2.61 & $2.32-2.93$ \\
\hline Histological type & & $<0.001$ & & \\
\hline Adenocarcinoma & 73.9 & & 1.00 & - \\
\hline
\end{tabular}


Table 3 (continued)

\begin{tabular}{lcrr}
\hline & Cumulative 5-year overall survival & $p$ value & HR \\
\hline Mucinous carcinoma & 66.2 & & 1.41 \\
Signet ring cell carcinoma & 21.9 & $4.21-1.63$ \\
CRM involvement & & $<0.001$ & $2.74-6.35$ \\
Absent & 75.0 & & 1.00 \\
Present & 53.5 & & 2.24 \\
Missing & 73.1 & 0.007 & 1.17 \\
Postoperative CTx & & & $1.97-2.56$ \\
No & 72.7 & & $1.04-1.32$ \\
Yes & 77.4 & & 0.78 \\
\hline
\end{tabular}

$S C-R T$ short-course radiation therapy, $C R T$ chemoradiation therapy, $C R M$ circumferential resection margin, $C T x$ chemotherapy

${ }^{\text {a }}$ Log-rank test

${ }^{\dagger} \mathrm{SC}-\mathrm{RT}$ vs. CRT

\section{Survival analysis}

Median follow-up was 28 months (range 0-84 months) and 1949 deaths were recorded (16.3\%). Cumulative 5-year overall survival was $73 \%$ (Table 3 ). The surgery-only group showed worse overall survival than the SC-RT and CRT groups $(64 \%, 76 \%$, and $74 \%$ for surgery only, SC-RT, and CRT, respectively; $p<0.001)$. However, there was no significant difference between patients treated with SC-RT vs. CRT $(p=0.147)$.

Clinical stage before neoadjuvant therapy was significantly associated with overall survival, although the hazard ratios are lower than those for pathological stage, and in the study population, the hazard ratios do not consistently increase with clinical stage in contrast to pathological stage, suggesting that the prognostic value of clinical stage is limited (HR 1.00, HR 1.46, and HR 1.38 for clinical TNM stages I, II, and III, respectively; and HR 0.62, HR 1.00, HR 1.76, and HR 2.61 for pathological TNM stages 0 , I, II, and III, respectively).

Figure 2a-c show stage-specific overall survival for patients with surgery only, SC-RT, and CRT. Survival was worst in the surgery-only group (cumulative 5-year survival 77\%, $63 \%$, and $52 \%$ for pathological stages I, II, and III, respectively; $p \leq 0.003$ compared with SC-RT and CRT). SC-RT-treated patients with pathological stage I disease had similar overall survival as same-stage patients in the CRT group (cumulative 5 -year survival $85 \%$ vs. $85 \%$, respectively; $p=0.167$ ). After CRT overall survival was comparable in patients with pathological stage I and those who reached a pCR (cumulative 5year survival $85 \%$ vs. $89 \%$ respectively; $p=0.113$ ). The SCRT group showed better survival than the CRT group for patients with pathological stage II (cumulative 5-year survival $77 \%$ vs. $68 \%$ for SC-RT vs. CRT, respectively; $p=0.002$ ) and stage III (cumulative 5-year survival $67 \%$ vs. $58 \%$ for SC-RT vs. CRT, respectively; $p<0.001$ ).
The multivariable analysis (Table 4) showed that CRT was independently associated with a higher mortality compared with SC-RT in patients with pathological stage II (HR 1.57 [95\% CI 1.27-1.95]; $p<0.001$ ) and stage III (HR 1.43 [95\% CI $1.23-1.70] ; p<0.001$ ), but not in those with stage I (HR 0.99 [95\%CI 0.77-1.27]; $p=0.146$ ). The hazard ratio for patients with surgery only was also increased compared with SC-RT for patients with pathological stage II (HR 1.67 [95\% CI 1.352.08 ]; $p<0.001$ ) and stage III (HR 1.60 [95\%CI 1.36-1.87]; $p<0.001$ ), but not stage I (HR 1.25 [95\%CI 0.99-1.59]; $p=$ $0.137)$.

\section{Discussion}

In this population-based study, using data from the Netherlands Cancer Registry, long-term stage-specific survival data was analyzed from 11,925 RC patients who underwent TME surgery with or without preoperative treatment consisting of either SC-RT or CRT. Patients with downstaging to pathological stage I disease after CRT had an excellent 5year overall survival which was similar as in SC-RT-treated patients without downstaging (85\%). For patients with pathological stages II and III, survival was significantly worse after CRT $(68 \%$ and $58 \%)$ compared with SC-RT (77\% and 67\%). In addition, clinical staging was a poor predictor of pathological stage based on the large discrepancies between clinical and pathological stages in the surgery-only group.

In the study period, the national clinical guideline [18] recommended preoperative SC-RT with $5 \times 5$ Gy and surgery within 1 week for primarily resectable RC (with the exception of cT1N0 tumors) and long-course CRT consisting of 4550 Gy given in 25 fractions of 1.8-2.0 Gy per day with concurrent oral capecitabine for locally advanced RC (see "Patients and methods" section for details). Patients treated 
Fig. 2 Overall survival for patients treated with surgery only, SC-RT, or CRT. a Pathological stage I. b Pathological stage II. c Pathological stage III. SC-RT, short-course radiation therapy; CRT, chemoradiation therapy a

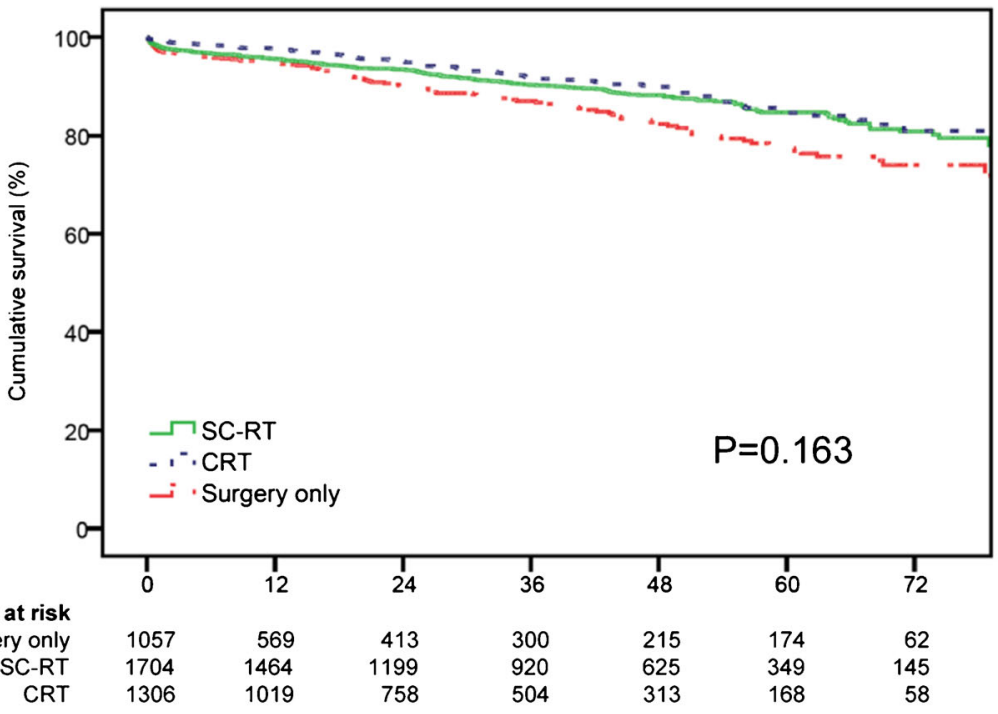

b

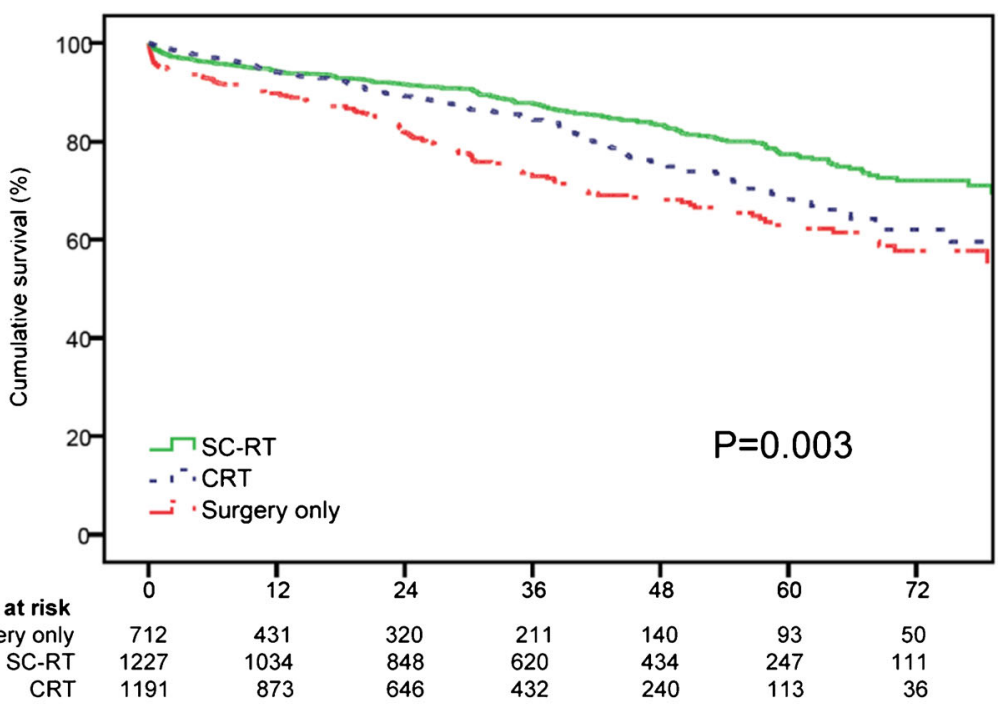

C

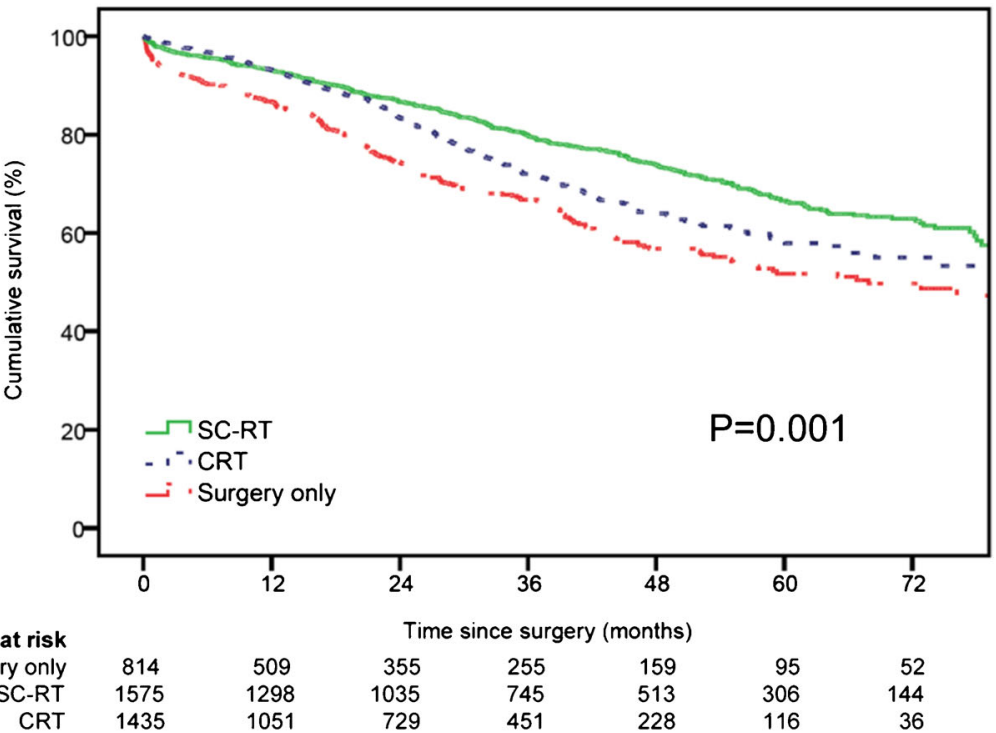


Table 4 Multivariable Cox regression analysis for overall survival of patients with pathological TNM stages I-III

\begin{tabular}{|c|c|c|c|c|c|c|c|c|c|}
\hline & \multicolumn{3}{|c|}{ (y)pTNM stage I } & \multicolumn{3}{|c|}{ (y)pTNM stage II } & \multicolumn{3}{|c|}{ (y)pTNM stage III } \\
\hline & HR & $95 \% \mathrm{CI}$ & $p$ value & HR & $95 \% \mathrm{CI}$ & $p$ value & HR & $95 \% \mathrm{CI}$ & $p$ value \\
\hline Preoperative therapy & & & 0.146 & & & $<0.001$ & & & $<0.001$ \\
\hline SC-RT & 1.00 & - & & 1.00 & - & & 1.00 & - & \\
\hline CRT & 0.99 & $0.77-1.27$ & & 1.57 & $1.27-1.95$ & & 1.43 & $1.23-1.70$ & \\
\hline None (surgery only) & 1.25 & $0.99-1.59$ & & 1.67 & $1.35-2.08$ & & 1.60 & $1.36-1.87$ & \\
\hline Gender & & & $<0.001$ & & & 0.007 & & & $<0.001$ \\
\hline Male & 1.00 & - & & 1.00 & - & & 1.00 & - & \\
\hline Female & 0.61 & $0.49-0.76$ & & 0.78 & $0.65-0.94$ & & 0.77 & $0.67-0.89$ & \\
\hline Age at diagnosis & & & $<0.001$ & & & $<0.001$ & & & $<0.001$ \\
\hline $0-44$ & 0.81 & $0.24-2.71$ & & 0.80 & $0.37-1.74$ & & 0.97 & $0.61-1.53$ & \\
\hline $45-59$ & 1.00 & - & & 1.00 & - & & 1.00 & - & \\
\hline $60-74$ & 2.99 & $1.95-4.59$ & & 1.23 & $0.94-1.61$ & & 1.35 & $1.12-1.63$ & \\
\hline $75+$ & 7.88 & $5.14-12.10$ & & 2.89 & $2.20-3.79$ & & 2.81 & $2.29-3.45$ & \\
\hline Type of resection & & & 0.147 & & & 0.025 & & & 0.002 \\
\hline Sphincter saving & 1.00 & - & & 1.00 & - & & 1.00 & - & \\
\hline Non-sphincter saving & 1.17 & $0.95-1.45$ & & 1.24 & $1.03-1.49$ & & 1.25 & $1.09-1.44$ & \\
\hline pT category & & & 0.588 & & & $<0.001$ & & & $<0.001$ \\
\hline pT0 & - & - & & - & - & & 1.48 & $0.75-2.90$ & \\
\hline pT1 & 1.00 & - & & - & - & & 1.00 & - & \\
\hline pT2 & 0.93 & $0.73-1.20$ & & - & - & & 1.20 & $0.75-1.92$ & \\
\hline pT3 & - & - & & 1.00 & - & & 1.91 & $1.22-3.00$ & \\
\hline pT4 & - & - & & 1.79 & $1.32-2.42$ & & 3.03 & $1.85-4.97$ & \\
\hline pN category & & & & & & & & & $<0.001$ \\
\hline $\mathrm{pN} 1$ & - & - & & - & - & & 1.00 & - & \\
\hline $\mathrm{pN} 2$ & - & - & & - & - & & 1.88 & $1.65-2.15$ & \\
\hline Histological type & & & 0.031 & & & 0.176 & & & 0.022 \\
\hline Adenocarcinoma & 1.00 & - & & 1.00 & - & & 1.00 & - & \\
\hline Mucinous carcinoma & 0.78 & $0.48-1.25$ & & 1.15 & $0.87-1.52$ & & 1.16 & $0.95-1.41$ & \\
\hline Signet ring cell carcinoma & 11.29 & $1.56-81.70$ & & 2.57 & $0.82-8.07$ & & 1.85 & $1.13-3.03$ & \\
\hline CRM involvement & & & 0.040 & & & 0.001 & & & $<0.001$ \\
\hline Absent & 1.00 & - & & 1.00 & - & & 1.00 & - & \\
\hline Present & 1.76 & $1.14-2.71$ & & 1.61 & $1.25-2.07$ & & 1.54 & $1.29-1.84$ & \\
\hline Missing & 1.03 & $0.80-1.33$ & & 1.23 & $0.98-1.54$ & & 1.15 & $0.96-1.38$ & \\
\hline Postoperative CTx & & & 0.474 & & & 0.008 & & & $<0.001$ \\
\hline No & 1.00 & - & & 1.00 & - & & 1.00 & - & \\
\hline Yes & 0.60 & $0.15-2.43$ & & 0.30 & $0.13-0.73$ & & 0.56 & $0.46-0.69$ & \\
\hline
\end{tabular}

$p$ pathological, $S C$ - $R T$ short-course radiation therapy, $C R T$ chemoradiation therapy, $A C$ adenocarcinoma, $M C$ mucinous carcinoma, $S R C C$ signet ring cell carcinoma, $C R M$ circumferential resection margin, $C T x$ chemotherapy

with surgery only in this period either had cT1N0 disease or were unfit or did not give consent to undergo the indicated preoperative therapy. Indeed, patients in the surgery-only group were found to be substantially older and had more comorbidity compared with both the SC-RT and CRT groups. These patients were therefore considered to be unsuitable as a control population in the current study.

On the other hand, the comparison of the SC-RT- and CRTtreated patients in this study yields some interesting results.
Although some small downstaging effect on T-stage and nodal downstaging have been reported in randomized trials after SC-RT with immediate surgery $[13,14]$, the SC-RT-treated patients in the current study all had an overall treatment time not exceeding 10 days, and evidence from a large randomized controlled trial showed that tumor and nodal downstaging do not occur in this short timeframe [16]. Furthermore, stage-specific 10-year overall survival was shown to be similar in randomized patients with preoperative SC-RT and those 
with surgery only or surgery with selective postoperative CRT [12-14]. This lack of downstaging and absence of a survival difference suggest that the SC-RT-treated patients in the current study may be regarded best as pTNM rather than ypTNM [19].

The observed difference in stage-specific survival between patients treated with CRT (substantial downstaging) and SCRT (no downstaging) was substantial and highly significant, and the effect was independent of several known possible confounders. However, selection bias may be a concern when interpreting these results. The inherently higher levels of treatment-induced toxicity caused by CRT may motivate clinicians to withhold this treatment in elderly patients with comorbidity, whereas the same comorbidity level would not preclude a treatment with much less toxic SC-RT. Unfortunately, comorbidity data was not available in the majority of patients and the results of the multivariable analysis could therefore not be corrected for this confounder. However, the subset analysis of patients with available comorbidity data showed that comorbidity levels were higher in the SC-RT than in the CRT group. As a consequence, the SC-RT group as a whole may be expected to show a bias towards a worse prognosis compared with the CRT group. However, the multivariable analysis showed the direct opposite with a better prognosis in the SC-RT group for patients with stage II and III disease. The observed survival differences may therefore be expected to be even larger if the results could be adjusted for comorbidity.

The introduction of preoperative CRT for RC which has resulted in tumor downstaging in a substantial proportion of patients has not resulted in improved survival compared with selective postoperative CRT [20]. The stage-specific outcome differences between the groups in this study are therefore not based on a therapeutic effect of the preoperative treatment, but are probably best explained by pathological stage migration. Patients with nodal disease may undergo sterilization of involved LN after CRT resulting in classification as pathological stage I or II disease instead of stage III.

Patients with downstaging to ypTNM stage I reflect a selection of treatment-sensitive tumors. The excellent survival observed in these patients, which is similar to SC-RT-treated pTNM stage I patients, suggests that potential occult disease or metastases also undergo substantial regression in patients with treatment-sensitive tumors. As a consequence, the observed mortality will increase in the ypTNM stage III patients with residual nodal metastases, since this group constitutes a selection of patients with treatment-resistant tumors. Furthermore, mortality can also be expected to increase in the ypTNM stage II group after CRT. This group is enriched with cases that had nodal disease at baseline, with higher risk of occult residual disease but with only intermediate regression to therapy, and this may correspond to intermediate regression of potential occult residual disease as well. This effect, called "the reverse of the Will Rogers phenomenon," has been described before with data from the German CAO/ARO/AIO-94 trial, showing that patients with pathological stage II disease after preoperative CRT had worse overall survival than same-stage patients from the control arm treated with selective postoperative CRT [21].

A limitation to the current study is that it is not possible to determine the exact rate of stage migration in CRT-treated patients, since clinical staging (especially $\mathrm{cN}$ category) is notoriously unreliable [22-25]. Indeed, data from this study showed large discrepancies between clinical and pathological stages in the surgery-only group (no downstaging by definition) with pathologically confirmed LN metastases in only $57 \%$ of patients with clinical stage III disease. The differences between clinical and pathological stages in the surgery-only and SC-RT groups and at least a part of the variation observed in the CRT group are therefore probably related to the imprecision of clinical staging and not to actual stage migration. This imprecision is reflected in the relatively limited prognostic value of clinical stage (cTNM) compared with definitive pathological stage ((y)pTNM) observed in this study. Another important restriction is the lack of an adequate pTNM control group, due to the high level of selection bias in patients treated with surgery only.

Furthermore, precise details regarding chemotherapy types and doses received were not available for individual patients, since the national cancer registry does not document this information. It is likely that a part of individual patients in the long-course CRT group received doses that are not equal to the recommended dose due to toxicity issues. In addition, it is possible that some patients in this group received additional chemotherapeutic agents besides capecitabine as part of a clinical trial. Unfortunately, the impact of these minor treatment variations on the results of this study cannot be ascertained.

In conclusion, this population-based study provides evidence that pathological stage I after preoperative CRT for RC is associated with an excellent prognosis, which is comparable with reaching a pCR and similar to same-stage SC-RT-treated patients without tumor regression. In patients with pathological stage II and III disease after CRT, the prognosis is worse than after SC-RT with immediate surgery. These results contain important prognostic information for individual patients and physicians and may have consequences for predictive models. Staging systems, such as TNM, should therefore take stage-specific survival differences between 
patients treated with different preoperative therapy regimens into account.

\section{Compliance with ethical standards}

Conflict of interest The authors declare that they have no conflict of interest.

Open Access This article is distributed under the terms of the Creative Commons Attribution 4.0 International License (http:// creativecommons.org/licenses/by/4.0/), which permits unrestricted use, distribution, and reproduction in any medium, provided you give appropriate credit to the original author(s) and the source, provide a link to the Creative Commons license, and indicate if changes were made.

\section{References}

1. Sauer R, Becker H, Hohenberger W, Rodel C, Wittekind C, Fietkau $R$ et al (2004) Preoperative versus postoperative chemoradiotherapy for rectal cancer. N Engl J Med 351:1731-1740

2. Gerard JP, Conroy T, Bonnetain F, Bouche O, Chapet O, ClosonDejardin MT et al (2006) Preoperative radiotherapy with or without concurrent fluorouracil and leucovorin in T3-4 rectal cancers: results of FFCD 9203. J Clin Oncol 24:4620-4625

3. Nagtegaal ID, Gosens MJ, Marijnen CA, Rutten HJ, van de Velde CJ, van Krieken JH (2007) Combinations of tumor and treatment parameters are more discriminative for prognosis than the present TNM system in rectal cancer. J Clin Oncol 25:1647-1650

4. de Bruin AF, Nuyttens JJ, Ferenschild FT, Planting AS, Verhoef C, de Wilt JH (2008) Preoperative chemoradiation with capecitabine in locally advanced rectal cancer. Neth J Med 66:71-76

5. Hugen N, van de Velde CJ, Bosch SL, Futterer JJ, Elferink MA, Marijnen CA et al (2015) Modern treatment of rectal cancer closes the gap between common adenocarcinoma and mucinous carcinoma. Ann Surg Oncol 22:2669-2676

6. Maas M, Nelemans PJ, Valentini V, Das P, Rodel C, Kuo LJ et al (2010) Long-term outcome in patients with a pathological complete response after chemoradiation for rectal cancer: a pooled analysis of individual patient data. Lancet Oncol 11:835-844

7. Rombouts AJ, Hugen N, Elferink MA, Nagtegaal ID, de Wilt JH (2016) Treatment interval between neoadjuvant chemoradiotherapy and surgery in rectal cancer patients: a population-based study. Ann Surg Oncol 23:3593-3601

8. Alves-Ferreira PC, de Campos-Lobato LF, Zutshi M, Hull T, Gurland B (2011) Total abdominal colectomy has a similar shortterm outcome profile regardless of indication: data from the National Surgical Quality Improvement Program. Am Surg 77: $1613-1618$

9. Rullier A, Laurent C, Capdepont M, Vendrely V, Bioulac-Sage P, Rullier E (2010) Impact of tumor response on survival after radiochemotherapy in locally advanced rectal carcinoma. Am J Surg Pathol 34:562-568

10. Sobin LH (ed) (2009) TNM classification of malignant tumours, 7 th edn. West Sussex, John Wiley and Sons Ltd

11. Edge S (2010) AJCC cancer staging handbook, 7th edn. Springer, Chicago

12. van Gijn W, Marijnen CA, Nagtegaal ID, Kranenbarg EM, Putter H, Wiggers T, Rutten HJ, Påhlman L, Glimelius B, van de Velde C, Dutch Colorectal Cancer Group (2011) Preoperative radiotherapy combined with total mesorectal excision for resectable rectal cancer: 12-year follow-up of the multicentre, randomised controlled TME trial. Lancet Oncol 12:575-582

13. Sebag-Montefiore D, Stephens RJ, Steele R, Monson J, Grieve R, Khanna S, Quirke P, Couture J, de Metz C, Myint AS, Bessell E, Griffiths G, Thompson LC, Parmar M (2009) Preoperative radiotherapy versus selective postoperative chemoradiotherapy in patients with rectal cancer (MRC CR07 and NCIC-CTG C016): a multicentre, randomised trial. Lancet 373:811-820

14. Martling A, Holm T, Johansson H, Rutqvist LE, Cedermark B, Stockholm Colorectal Cancer Study G (2001) The Stockholm II trial on preoperative radiotherapy in rectal carcinoma: long-term follow-up of a population-based study. Cancer 92:896-902

15. Bujko K, Nowacki MP, Nasierowska-Guttmejer A, Michalski W, Bebenek M, Kryj M (2006) Long-term results of a randomized trial comparing preoperative short-course radiotherapy with preoperative conventionally fractionated chemoradiation for rectal cancer. Br J Surg 93:1215-1223

16. Marijnen CA, Nagtegaal ID, Klein Kranenbarg E, Hermans J, van de Velde CJ, Leer JW et al (2001) No downstaging after short-term preoperative radiotherapy in rectal cancer patients. J Clin Oncol 19: 1976-1984

17. Bujko K, Nowacki MP, Nasierowska-Guttmejer A, Kepka L, Winkler-Spytkowska B, Suwinski R et al (2005) Prediction of mesorectal nodal metastases after chemoradiation for rectal cancer: results of a randomised trial: implication for subsequent local excision. Radiother Oncol 76:234-240

18. Rectal cancer. National guideline. Version 2.0. http://heelkunde.nl/ sites/heelkunde.n1/files/richtlijnen-definitief/Rectumcarcinoom 2008.pdf 2008. Accessed 16 March 2016

19. Nagtegaal ID, Tot T, Jayne DG, McShane P, Nihlberg A, Marshall HC et al (2011) Lymph nodes, tumor deposits, and TNM: are we getting better? J Clin Oncol 29:2487-2492

20. Sauer R, Liersch T, Merkel S, Fietkau R, Hohenberger W, Hess C, Becker H, Raab HR, Villanueva MT, Witzigmann H, Wittekind C, Beissbarth T, Rödel C (2012) Preoperative versus postoperative chemoradiotherapy for locally advanced rectal cancer: results of the German CAO/ARO/AIO-94 randomized phase III trial after a median follow-up of 11 years. J Clin Oncol 30:1926-1933

21. Fokas E, Liersch T, Fietkau R, Hohenberger W, Hess C, Becker H, Sauer R, Wittekind C, Rödel C (2015) Downstage migration after neoadjuvant chemoradiotherapy for rectal cancer: the reverse of the Will Rogers phenomenon? Cancer 121:1724-1727

22. Guillem JG, Diaz-Gonzalez JA, Minsky BD, Valentini V, Jeong SY, Rodriguez-Bigas MA et al (2008) cT3N0 rectal cancer: potential overtreatment with preoperative chemoradiotherapy is warranted. $\mathrm{J}$ Clin Oncol 26:368-373

23. Bedrosian I, Rodriguez-Bigas MA, Feig B, Hunt KK, Ellis L, Curley SA et al (2004) Predicting the node-negative mesorectum after preoperative chemoradiation for locally advanced rectal carcinoma. J Gastrointest Surg 8:56-62 discussion 62-53

24. Leibold T, Shia J, Ruo L, Minsky BD, Akhurst T, Gollub MJ, Ginsberg MS, Larson S, Riedel E, Wong WD, Guillem JG (2008) Prognostic implications of the distribution of lymph node metastases in rectal cancer after neoadjuvant chemoradiotherapy. J Clin Oncol 26:2106-2111

25. Bipat S, Glas AS, Slors FJ, Zwinderman AH, Bossuyt PM, Stoker J (2004) Rectal cancer: local staging and assessment of lymph node involvement with endoluminal US, CT, and MR imaging-a metaanalysis. Radiology 232:773-783

Publisher's note Springer Nature remains neutral with regard to jurisdictional claims in published maps and institutional affiliations. 